\title{
Time to re-think our strategy with musculoskeletal disorders and workstation ergonomics
}

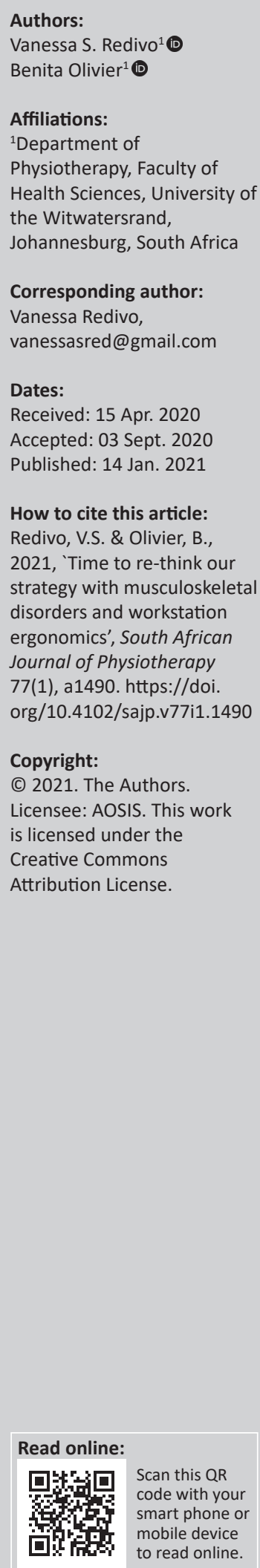

Background: The dramatic increase in visual display units (VDU) in the workplace over a 20year period is linked to the increased prevalence of musculoskeletal disorders (MSDs).

Objectives: The objective of our study was to compare ergonomic risk factors and workrelated psychosocial factors in VDU users with and without MSD.

Methods: Participants, with and without MSD, working with VDU for more than $4 \mathrm{~h}$ a day completed the Nordic Musculoskeletal Questionnaire and the Effort-Reward Imbalance Model and Over-commitment Questionnaire. The workstation of each participant was assessed for ergonomic risk factors using the Rapid Office Strain Assessment (ROSA).

Results: Sixty-eight VDU users with and 68 without MSDs participated. The workstation ergonomic risk factors as measured with the ROSA were similar for the two groups: $4.5 \pm 1.0$ for the MSD group and $4.3 \pm 0.8$ for the reference group $(p=0.10)$. The work-related psychosocial factors, namely over-commitment, were higher in the MSD group $(14.9 \pm 3.1)$ than in the reference group $(13.8 \pm 3.4 ; p=0.041)$.

Conclusions: As over-commitment is an indication of intrinsic factors and personal characteristics, the significant difference between the MSD group's over-commitment score and that of the reference group suggests that interventions to empower individuals are needed.

Clinical implications: Physiotherapists should only adjust ergonomic workstation risk factors when established as contributory to MSD, and should be cognisant of work-related or individual psychosocial factors that may impact the patient with MSD. The use of ergonomic advice to patients with MSD should be performed with caution, taking all the work place risk factors for MSD into account.

Keywords: musculoskeletal disorders; ergonomics; visual-display-unit users; ROSA; psychosocial factors; effort-reward imbalance.

\section{Introduction}

There has been a dramatic increase in visual display units (VDU) in the work place over a 20-year period, as much as doubling the percentage of users (Kaliniene et al. 2013; Sonne, Villalta \& Andrews 2012; Wahlstrom 2005). A VDU user is defined as an individual working with a VDU that involves the use of a keyboard and mouse, or both (Collins Dictionary 2018). The prevalence of musculoskeletal disorders (MSDs) in VDU users has increased; one of the many contributory factors includes the increased use of VDU (Ranasinghe et al. 2011). This increase in MSD has resulted in an increase in sick days (absence from work), reduced efficiency, an increased burden of disease and loss to the economy (Green 2008; Matos \& Arezes 2015; Van Eerd et al. 2016). Workrelated MSD continues to pose challenges to the health system (Silva et al. 2014) and leads to disability and compensation claims (Maakip, Keegel \& Oakman 2017; Widanarko et al. 2014).

The reported prevalence rate of MSD may also vary according to the type of occupation and the sample population studied (De Cássia Pereira Fernandes et al. 2016; Huisstede et al. 2006). Visual display unit users have shown increased upper quadrant prevalence rates in comparison to lower back pain (Ardahan \& Simsek 2016; Das \& Ghosh 2010; Green 2008; Ranasinghe et al. 2011; Wu et al. 2012), specifically, disorders of the neck (Green 2008; Wu et al. 2012). Multi-site pain is also prevalent in VDU users (Neupane \& Nygård 2017; Oha et al. 2014).

Work-related MSD has been documented to be multi-factorial (Matos \& Arezes 2015; Oha et al. 2014; Sonne et al. 2012; Wahlstedt et al. 2010), and includes physical factors like muscular load, non-neutral postures, static postures, extreme positions, repetitive movements, force, visual 
demands, the duration of time spent at work, the duration of time spent in front of the VDU, the workstation set-up, as well as associated psychosocial work demands, such as mental stress, job control, support, work style and technique, perceived tiredness, inactivity or individual factors such as smoking, socioeconomic factors, sex and personal demographics (Bruno Garza \& Young 2015; Das \& Ghosh 2010; Green 2008; Korhonen et al. 2003; Ranasinghe et al. 2011; Rodrigues, Leite, Lelisa \& Chaves 2017; Sun, Nimbarte \& Motabar 2017; Wahlstedt et al. 2010; Wahlstrom 2005; Wu et al. 2012; Zakerian \& Subramanian 2011).

A poor ergonomic workstation has been shown to increase muscular load and muscular activity causing an increase in MSD (Sun et al. 2017; Wahlstrom 2005). The physical factors or load on the biomechanical system are hypothesised to cause tissue damage and inflammation, thus resulting in MSD (Bruno Garza \& Young 2015). Quantifying the ergonomic risk of a workstation is a method to cost-effectively implement and manage MSD in the work place (Sonne et al. 2012) and a plausible deduction would seemingly be to address the ergonomic workstation set up as a method to prevent, as well as address MSD (Ranasinghe et al. 2011). However, there is still conflicting evidence that shows no correlation between workstation set up and MSD (Coelho et al. 2015; Klussmann et al. 2008; Lima \& Coelho 2018; Wu et al. 2012). Research that supports the general ergonomic advice provided to patients in South Africa is lacking, thus warranting further investigation in the South African population.

With regard to the workstation set up amongst VDU users, the comprehensive review, conducted by Woo, White and Lai (2016), included ergonomic guidelines and workstation arrangements from Australia, Canada, United States, Europe and Hong Kong. Woo et al. (2016) note that the studies use a baseline of anthropometrics and biomechanics to establish guidelines for computer workstation design. However, with the differences in anthropometrics in each country, the guidelines should allow optimal adjustment and be flexible for each end user. The review by Woo et al. (2016) does not cover any African, let alone South African standards, guidelines or studies. There is a need, therefore, to research the South African population anthropometrics within the workstation design framework in order to establish South African guidelines.

Specific ergonomic guidelines, including a neutral posture, monitor position, appropriate work surface, the use of supportive accessories, the correct type of chair and a satisfactory sitting position have been suggested in order to minimise the physical risk factors for MSD in the VDU user (Woo et al. 2016). The correlation of neck pain, disability and forward head posture has been established (Kim \& Kim 2016), and could be indicative of the effect of non-neutral postures. A constant neck flexion angle with the neck being held in a bent position has also been determined as a risk factor amongst VDU users for MSD of the neck (Sun et al.
2017; Wu et al. 2012). A neck flexion angle of $45^{\circ}$ has been found to significantly affect the upper and lower back, shoulders and feet and may lead to pain (Celik et al. 2018). The use of laptops increases neck flexion angles and limits the adjustability of the workstation (Werth \& Babski-Reeves 2014), and could affect work postures, bringing about discomfort and MSD. Sitting is a risk factor for lower back pain and other MSDs (Celik et al. 2018; Green 2008; Silva et al. 2014) and sitting for long periods in addition increases the risk for lower back pain (Silva et al. 2014).

Psychosocial factors influencing this multi-factorial problem have been an area of increased interest. The literature assessing psychosocial risk factors associated with MSD in VDU users highlights the following: computer-related problems, employees' level of job control and social interaction (Zakerian \& Subramanian 2011), increased work demand, greater work experience (Kaliniene et al. 2013), considerable demands associated with the job, limited job influence and development, low level of job satisfaction, poor interpersonal relationships and leadership (Yue et al. 2014), increased mental demands, low job control (Devereux, Vlachonikolis \& Buckle 2002), limited social support (Devereux et al. 2002; Wahlstedt et al. 2010), high demands and stress (Wahlstedt et al. 2010).

A tool to measure work-related psychosocial risk factors includes the Effort-Reward Imbalance Model and Overcommitment. The questionnaire was designed to clarify the impact of social and psychosocial factors on health and disease (Siegrist 1996), and has been successfully used on a mixed sample group, including healthcare workers, random sample of the general population, office workers, call centre operators, blue collar workers and police officers (De Jonge et al. 2008; Koch et al. 2014; Landolt et al. 2017). An EffortReward Ratio is used to assess potential imbalances between high effort and limited rewards (Siegrist 2012). Reward is the reciprocation of such effort, and has three defined sub-scales, namely esteem, promotion and security (Siegrist, Li \& Montano 2014). Over-commitment, an intrinsic factor, is said to refer to individuals, who have an excessive work-related commitment, as well as a need for approval (Siegrist et al. 2004) and could be elevated in those who have a misconception of perceived demands, as well as poor personal coping strategies (Siegrist 2012). Over-commitment can be defined as a person-specific component (Van Vegchel et al. 2005), where Effort-Reward is related to structural work components (Siegrist et al. 2004).

Discovering which factors play a role in MSD, and the relationship between these factors and MSD could result in better intervention methods to address and manage MSD. The relationship between MSD, ergonomic workstation set up and psychosocial factors has not been established in the VDU user in the work place in South Africa. To the authors' knowledge, there has been only one study conducted in South Africa within a VDU population and ergonomic setup. This was a case study, and pain and discomfort were 
found to decrease with an optimal ergonomic workstation set-up (Van Vledder \& Louw 2015). Other studies related to MSD in the South African population are often conducted amongst blue-collared workers. When comparing high income and middle-to-low income countries, there appear to be differences between prevalence rates and the site or location and the type of MSD observed in public sector office workers. The reason for these differences in MSD in the office worker may be because of specific sociocultural factors (Maakip et al. 2017). This warrants further research in the South African population.

The workstation set-up has been mentioned as a risk factor; however, findings in this respect are shown to be inconsistent (Coelho et al. 2015; Klussmann et al. 2008; Lima \& Coelho 2018; Wu et al. 2012). As such with the added interest of the influence of psychosocial risk factors, the relationship between ergonomic risk factors and psychosocial risk factors in MSD and a reference group needs to be established. Thus, the objective of our study was to compare ergonomic risk factors and work-related psychosocial factors in VDU users with and without MSD in the South African population.

\section{Methods}

This cross-sectional, observational study was conducted at the workstations of three companies in Pretoria and Johannesburg in the Gauteng province. A sample of convenience consisting of VDU users in the fields of administration, information technology and research was included based on consent received from the human resource departments. The three companies were the only companies that allowed access to the employees of a large group of companies that were initially approached to participate in our study.

Participants were included if they were 18 years old and above, using a VDU at work for more than $4 \mathrm{~h}$ a day (Lapointe et al. 2013; Mirzaei et al. 2014; Oha et al. 2014; Poochada \& Chaiklieng 2015), working more than 12 months in their current job or a similar occupation. The exposure for $4 \mathrm{~h}$ or more was considered to be sufficient exposure to the risk factors for MSD in similar studies of VDU users (Lapointe et al. 2013; Mirzaei et al. 2014; Oha et al. 2014; Poochada \& Chaiklieng 2015). Employees who had undergone surgery for MSD in the previous 2 years, or were undergoing mental health treatment, including but not limited to depression and anxiety were excluded. The sample size required to analyse the difference between the MSD and reference group was 128 , with 64 participants in each group. This was calculated by $G *$ Power (version 3.1.9.2) with a power probability of 0.8 at the 0.05 alpha level (two-tailed design), using a moderate effect size (Cohen's $d=0.5$ ) and an equal allocation of participants in each group.

\section{Outcome measures}

All participants completed a self-report questionnaire consisting of questions relating to individual demographics (age, sex, height, weight and handedness) using an amended
Cultural and Psychosocial Influences on Disability (CUPID) questionnaire (Coggon et al. 2012) as well as the Nordic Musculoskeletal Questionnaire (Kuorinka et al. 1987) to determine MSD. The Nordic Musculoskeletal Questionnaire is also considered to be an adequate screening tool for comparing the sensitivity of the responses to the questionnaire with the results of the clinical examinations. The questionnaire showed a sensitivity to MSD between $66 \%$ and $92 \%$ (Crawford 2007). The participant was asked whether to his or her knowledge the MSD was related to factors other than work in order to allow for the correct allocation of participants to either the MSD group or the reference group. Should the participant not have recollection of any other cause of MSD injury, it was considered workrelated MSD, and only a small number of the participants did not specify the cause of MSD.

Work-related psychosocial factors were assessed using the Effort-Reward Imbalance Model and Over-commitment Questionnaire. High effort and limited rewards produce a ratio of more than 1.0, or non-reciprocity, or limited effort and high level of reward is defined as a ratio less than 1.0. The questionnaire includes 24 questions in total, five questions related to effort, 11 questions related to reward and six for over-commitment on a four-point Likert scale (Siegrist 1996). The Effort-Reward Ratio is calculated by the sum of the efforts as an enumerator and the sum of the rewards as the denominator. The denominator score was multiplied by a correction factor of 0.4545 to adjust for unequal items between effort and reward. Effort, total reward, reward subscales (esteem, promotion and security) and over-commitment were calculated by the sum of the scores of each construct as defined in the questionnaire (Siegrist 2012). Internal consistency in respect of an effort score of alpha 0.74, a reward score of alpha 0.82 and an over-commitment score between 0.73 and 0.78 is considered to be satisfactory (De Jonge et al. 2008)

Ergonomic risk factors were measured using the Rapid Office Strain Assessment (ROSA). The ROSA is meant to quickly quantify risks in a typical workstation into low, medium and high. The risk assessment is aimed to assist the user to prioritise changes that are based on ergonomic standards, as well as discomfort scores (Sonne et al. 2012). During the development of the ROSA, the intra and inter-observer reliability levels were assessed, with the intra-observer reliability of the final ROSA score being 0.91 (Sonne et al. 2012). A final score is a calculation of the risk relating to the chair, and peripherals including a score of the monitor, phone, keyboard and mouse. Duration spent using the various components of the workstation affects the overall score. One-hour continuous use or more than $4 \mathrm{~h}$ a day results in an additional point awarded to each component. A score of five or higher requires immediate adjustments (Sonne et al. 2012). Considering its specificity to computer use in the work place, ROSA has been used with great success in other studies (Matos \& Arezes 2015; Poochada \& Chaiklieng 2015). Figure 1 illustrates the ROSA scoring system. 


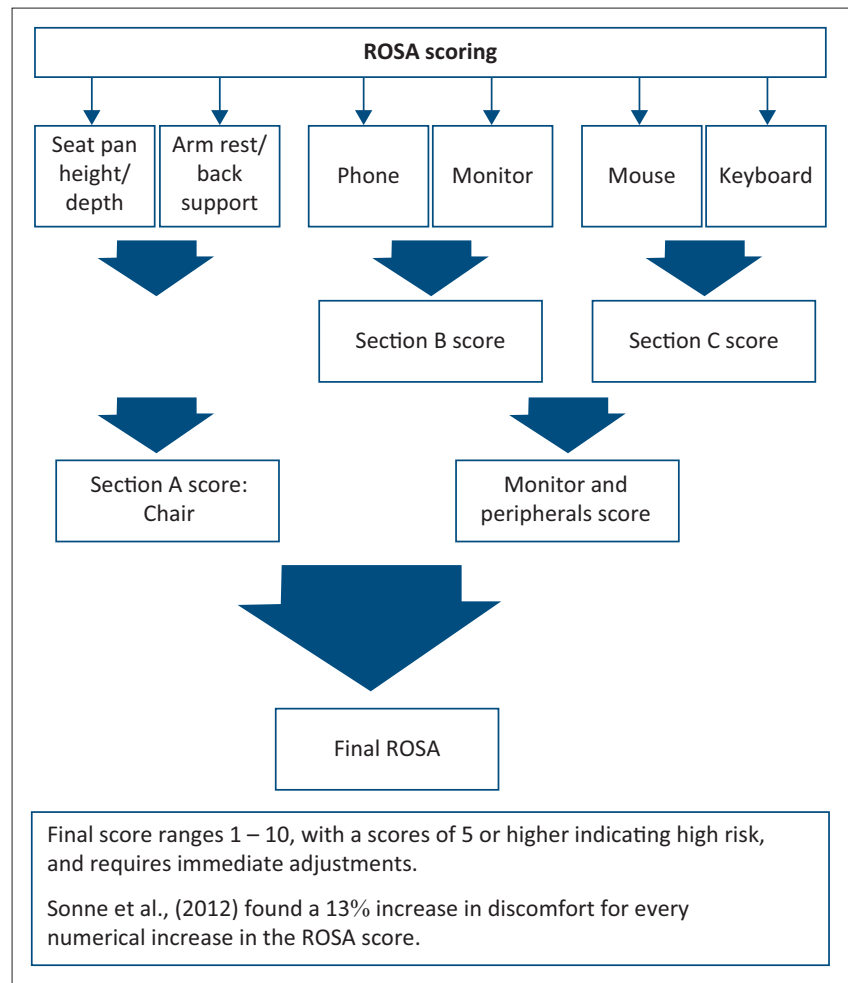

Source: Sonne, M., Villalta, D.L. \& Andrews, D.M., 2012, 'Development and evaluation of an office ergonomic risk checklist : ROSA - Rapid office strain assessment', Applied Ergonomics 43(1), 98-108. https://doi.org/10.1016/j.apergo.2011.03.008

ROSA, rapid office strain assessment.

FIGURE 1: Diagrammatic presentation of the rapid office strain assessment scoring system.

\section{Procedure}

The study procedure is depicted in Figure 2. Prior to the data collection, permission to access employees was obtained from the human resource departments of the companies in question. A pilot study was performed in order to discern any areas of bias and to streamline the data collection process. As no changes were made to the procedures after the pilot study, data were analysed with the data collected in the main study.

Each participant was included in an onsite informed-consent information session, and only after the participant had signed consent to participate, the link to the online questionnaire was emailed to him or her. Had the employee declined to take part in our study, no link was sent and the first author approached the next employee. Research Electronic Data Capture (REDCap), a data collection and management platform (Harris et al. 2009), was used for online data collection. The participant completed the online self-reported questionnaires at his or her workstation.

Whilst the participants were completing the questionnaire, the first author observed the respective workstations and in each case completed the ROSA (Sonne et al. 2012). The ROSA does not need formal training; however, the first author was proficient in completing the ROSA. The ROSA was presented to all participants, regardless of any MSD complaints. At that point, the first author was blinded to the presence of MSD. Once the participant had completed all questionnaires online, at the end

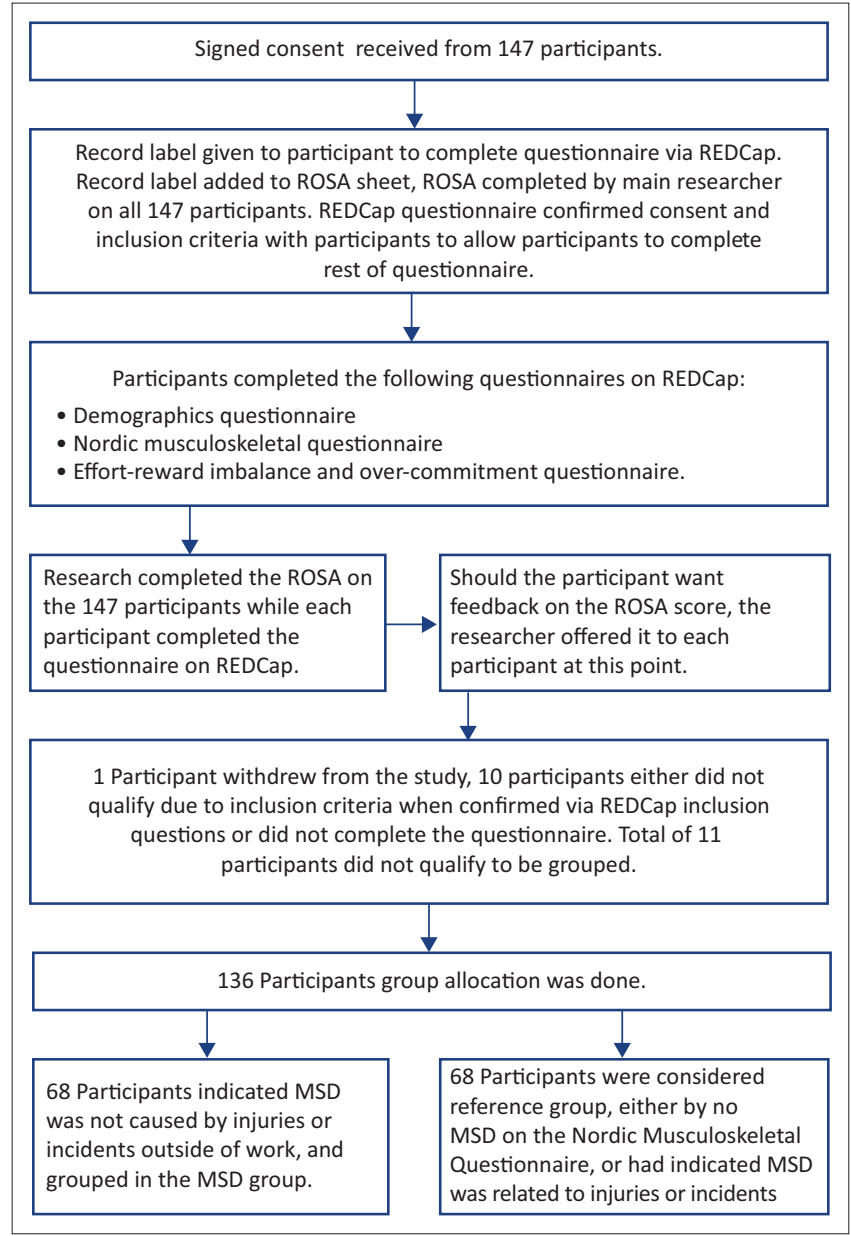

ROSA, rapid office strain assessment.

FIGURE 2: Flow diagram of study procedure.

of the session, feedback about ergonomic workstation risk factors and adjustments was given to all willing participants.

Only the first author dealt with the ROSA and ergonomic advice. This allowed for consistency in the application of the assessment tool. The first author completed 147 ROSA assessments; however, 10 participants did not qualify because of the inclusion criteria or did not complete the questionnaire on REDCap, and one participant withdrew from our study without giving a reason. The remaining 136 participants were grouped into the work-related MSD group, or the reference group either with no MSD or non-work related MSD. Two groups of 68 participants were formed.

\section{Data analysis}

Each variable was described in terms of its mean, standard deviation, frequency and percentages, as relevant, in the MSD and the reference group. The variables for individual demographics and anthropometrics included age, height, weight, body mass index (BMI), sex and handedness. Differences between the categorical variables of the MSD group and the reference group were analysed using Chi-squared tests. Independent sample t-tests were run to determine whether there were differences between the mean variable scores for the MSD group and the 
reference group. Missing data were not replaced and thus ignored in the analyses.

\section{Ethical consideration}

Ethical clearance was sought and obtained from the Human Research Ethics Committee (Medical) of the University of the Witwatersrand, Johannesburg (Clearance Certificate no. M171064).

\section{Results}

\section{Demographics and anthropometrics}

The two groups consisted of 68 participants each $(n=136)$. The MSD group consisted of $31(45.6 \%)$ females, and the reference group consisted of $27(39.7 \%)$ females $(p=0.603)$. The majority of participants were right-handed (MSD group $n=62 ; 91.2 \%$; reference group $n=65 ; 95.6 \% ; p=0.493$ ).

Table 1 reflects the demographics and anthropometrics, where no differences between the two groups in terms of mean values for age, height, weight and BMI and proportions for sex and handedness were found.

\section{Musculoskeletal disorders}

Table 2 shows the prevalence of MSD by location of pain as determined by the Musculoskeletal Nordic Questionnaire. The majority of participants had experienced neck pain in the previous 12 months as well as in the last 7 days.

Participants could indicate more than one site of MSD. More than one site of MSD was classified as multi-site MSD. The MSD group experienced a mean score for multi-site MSD of $2.6 \pm 1.4$. In terms of multi-site pain, 15 participants $(22.1 \%)$ experienced pain in one site, $22(32.4 \%)$ at two sites, 16 $(23.5 \%)$ at three sites, six $(8.8 \%)$ at four sites, seven $(10.3 \%)$ at five sites, one $(1.5 \%)$ at six sites and one $(1.5 \%)$ at seven sites.

TABLE 1: Group demographics and anthropometrics ( $n=136)$.

\begin{tabular}{lccccc}
\hline MSD group & & \multicolumn{2}{c}{ Reference group } & $p$ \\
\cline { 1 - 2 } Demographics & Mean \pm SD & & Demographics & Mean \pm SD & \\
\hline Age (years) $(n=68)$ & $33.3 \pm 8.5$ & & Age (years) $(n=68)$ & $35.3 \pm 8.7$ & 0.167 \\
Height $(\mathrm{m})(n=68)$ & $1.7 \pm 0.1$ & & Height $(\mathrm{m})(n=66)$ & $1.7 \pm 0.1$ & 0.992 \\
Weight $(\mathrm{kg})(n=68)$ & $75.9 \pm 15.7$ & & Weight $(\mathrm{kg})(n=67)$ & $75.3 \pm 13.6$ & 0.780 \\
BMI $\left(\mathrm{kg} / \mathrm{m}^{2}\right)(n=68)$ & $26.1 \pm 5.3$ & & BMI $\left(\mathrm{kg} / \mathrm{m}^{2}\right)(n=66)$ & $26.1 \pm 4.9$ & 0.986 \\
\hline
\end{tabular}

MSD, musculoskeletal disorders; BMI, body mass index; SD, standard deviation.

TABLE 2: Previous 12 months and 7 days prevalence in musculoskeletal disorders by location $(n=68)$.

\begin{tabular}{lccccc}
\hline Location & \multicolumn{2}{c}{ Previous $\mathbf{1 2}$ months } & & \multicolumn{2}{c}{ Previous 7 days } \\
\cline { 2 - 3 } \cline { 6 - 6 } & $\%$ & $\boldsymbol{n}$ & & $\%$ & $\boldsymbol{n}$ \\
\hline Neck & 69.1 & 47 & & 33.9 & 23 \\
Shoulder & 57.4 & 39 & & 27.9 & 19 \\
Upper back & 39.7 & 27 & & 16.2 & 11 \\
Elbow & 5.9 & 4 & & 2.9 & 2 \\
Wrists/hands & 25 & 17 & & 8.8 & 6 \\
Lower back & 41.2 & 28 & & 13.2 & 9 \\
Knee & 19.1 & 13 & & 7.4 & 5 \\
Ankle & 5.9 & 4 & & 1.5 & 1 \\
None & 0 & 0 & & 33.9 & 23 \\
\hline
\end{tabular}

\section{Work-related psychosocial risk factors}

Table 3 shows the mean values for scale of effort, total reward, the Effort-Reward Ratio, the reward sub-scales and the overcommitment scores for the MSD group and the reference group, respectively. The Effort-Reward Ratio for the MSD group as well as for the reference group was calculated as less than one; hence there were fewer efforts than rewards. The over-commitment score was significantly different ( $p=0.041$ ) where the MSD group achieved a higher mean over-commitment score as opposed to the reference group.

\section{Ergonomic risk factors}

The mean ROSA scores from both the MSD group and the reference group were under five. The mean final ROSA scores for the MSD group and the reference group were $4.5 \pm 1.0$ and $4.3 \pm 0.8(p=0.102)$, respectively. Table 4 shows the number of participants in the MSD group and the reference group in each ROSA final score grouping. Tables 5-7 indicate the sub-scores of the ROSA, Section A, B and C.

Zero scores were removed from the table to allow for ease of reading. A score of five or more indicates high risk and need for immediate adjustment. Not one participant had a score lower than three, or higher than seven.

\section{Discussion}

No differences in terms of demographics and anthropometrics between the MSD group and the reference group were found. This is in contrast to studies where age has been considered a risk factor (Celik et al. 2018; Collins \& O'Sullivan 2015; Kaliniene et al. 2013; Wu et al. 2012). As Kaliniene et al. (2013) noted, there is an increased risk of 2.37 for neck MSD between the ages of 40 and 49 years. The mean age of participants, of

TABLE 3: Effort-reward imbalance and over-commitment in the musculoskeletal disorders group $(n=68)$ and the reference group $(n=68)$.

\begin{tabular}{lcccc}
\hline Variables & Range & $\begin{array}{c}\text { MSD group } \\
\text { Mean } \pm \text { SD }\end{array}$ & $\begin{array}{c}\text { Reference group } \\
\text { Mean } \pm \text { SD }\end{array}$ & $p$ \\
\hline Effort-Reward Ratio & $<1$ or $>1$ & $0.9 \pm 0.2$ & $0.9 \pm 0.2$ & 0.287 \\
Effort & $6-24$ & $15.6 \pm 3.0$ & $14.8 \pm 2.3$ & 0.122 \\
Total reward & $10-40$ & $30.9 \pm 3.9$ & $30.8 \pm 3.7$ & 0.892 \\
Reward sub-scales & & & & \\
Reward-esteem & $4-16$ & $9.6 \pm 1.4$ & $9.6 \pm 1.3$ & 0.797 \\
Reward-promotion & $4-16$ & $11.8 \pm 1.9$ & $11.4 \pm 1.7$ & 0.587 \\
Reward-security & $2-8$ & $6.4 \pm 1.0$ & $6.4 \pm 1.2$ & 0.877 \\
Over-commitment & $6-25$ & $14.9 \pm 3.1$ & $13.8 \pm 3.4$ & $0.041^{*}$ \\
\hline
\end{tabular}

MSD, musculoskeletal disorders; SD, standard deviation; Range, minimum to maximum range of scores per construct as defined in the questionnaire.

$*$, statistically significant.

TABLE 4: Final rapid office strain assessment Score for musculoskeletal disorders group $(n=68)$ and reference group $(n=68)$.

\begin{tabular}{lcccccc}
\hline Score & \multicolumn{2}{c}{ MSD group } & & \multicolumn{2}{c}{ Reference group } \\
\cline { 2 - 3 } \cline { 5 - 6 } & $\mathbf{\%}$ & $\boldsymbol{n}$ & & $\mathbf{\%}$ & $\boldsymbol{n}$ \\
\hline 1 & 20.6 & 14 & & 23.5 & 16 \\
2 & 23.5 & 16 & & 30.9 & 21 \\
3 & 42.7 & 29 & & 42.7 & 29 \\
4 & 10.3 & 7 & & 2.9 & 2 \\
5 & 2.9 & 2 & & 0 & 0 \\
\hline
\end{tabular}

MSD, musculoskeletal disorder. 
TABLE 5: Sub-scores of the rapid office strain assessment (Section A).

\begin{tabular}{|c|c|c|c|c|c|c|c|c|c|c|c|c|}
\hline \multirow[t]{3}{*}{ Score } & \multicolumn{4}{|c|}{ Seat pan/height/depth } & \multicolumn{4}{|c|}{ Arm rest/back support } & \multicolumn{4}{|c|}{ Section A: Chair } \\
\hline & \multicolumn{2}{|c|}{ MSD } & \multicolumn{2}{|c|}{ Ref } & \multicolumn{2}{|c|}{ MSD } & \multicolumn{2}{|c|}{ Ref } & \multicolumn{2}{|c|}{ MSD } & \multicolumn{2}{|c|}{ Ref } \\
\hline & $\%$ & $n$ & $\%$ & $n$ & $\%$ & $n$ & $\%$ & $n$ & $\%$ & $n$ & $\%$ & $n$ \\
\hline 2 & 0.0 & 0 & 0.0 & 0 & 0.0 & 0 & 0.0 & 0 & 10.3 & 7 & 13.2 & 9 \\
\hline 3 & 69.1 & 47 & 72.1 & 49 & 17.7 & 12 & 16.2 & 11 & 29.4 & 20 & 30.9 & 21 \\
\hline 4 & 10.3 & 17 & 20.6 & 14 & 23.5 & 16 & 30.9 & 21 & 32.3 & 22 & 28.2 & 26 \\
\hline 5 & 0.0 & 0 & 4.4 & 3 & 35.3 & 24 & 36.8 & 25 & 17.7 & 12 & 16.2 & 11 \\
\hline 6 & 1.5 & 1 & 2.0 & 2 & 17.6 & 12 & 16.2 & 11 & 7.4 & 5 & 1.5 & 1 \\
\hline 7 & 4.4 & 3 & 0.0 & 0 & 5.9 & 4 & 0.0 & 0 & 2.9 & 2 & 0.0 & 0 \\
\hline
\end{tabular}

MSD, musculoskeletal disorders; Ref, reference group.

No comparison between sub-scores was undertaken as only the final ROSA score was validated in the literature. However, the sub-scores are presented to allow for discussion; Zero scores were removed from the table to allow for ease of reading.

Section A: Chair score and peripheral score combined provided the final ROSA score.

TABLE 6: Sub-scores of the rapid office strain assessment (Section B).

\begin{tabular}{|c|c|c|c|c|c|c|c|c|c|c|c|c|}
\hline \multirow[t]{3}{*}{ Score } & \multicolumn{4}{|c|}{ Monitor } & \multicolumn{4}{|c|}{ Phone } & \multicolumn{4}{|c|}{ Section B } \\
\hline & \multicolumn{2}{|c|}{ MSD } & \multicolumn{2}{|c|}{ Ref } & \multicolumn{2}{|c|}{ MSD } & \multicolumn{2}{|c|}{ Ref } & \multicolumn{2}{|c|}{ MSD } & \multicolumn{2}{|c|}{ Ref } \\
\hline & $\%$ & $n$ & $\%$ & $n$ & $\%$ & $n$ & $\%$ & $n$ & $\%$ & $n$ & $\%$ & $n$ \\
\hline 1 & 0.0 & 0 & 0.0 & 0 & 100 & 68 & 97.1 & 66 & 23.5 & 16 & 26.5 & 18 \\
\hline 2 & 10.3 & 17 & 27.9 & 19 & 0.0 & 0 & 1.5 & 1 & 32.3 & 22 & 35.3 & 24 \\
\hline 3 & 30.9 & 21 & 33.9 & 23 & 0.0 & 0 & 1.5 & 1 & 42.7 & 29 & 35.3 & 24 \\
\hline 4 & 42.7 & 29 & 36.8 & 25 & 0.0 & 0 & 0.0 & 0 & 1.5 & 1 & 2.9 & 2 \\
\hline 5 & 1.5 & 1 & 0.0 & 0 & 0.0 & 0 & 0.0 & 0 & 0.0 & 0 & 0.0 & 0 \\
\hline
\end{tabular}

MSD, musculoskeletal disorders; Ref, reference group.

No comparison between sub-scores was undertaken as only the final ROSA score was validated in the literature. However, the sub-scores are presented to allow for discussion; Zero scores were removed from the table to allow for ease of reading.

Section B later provided a peripheral score.

TABLE 7: Sub-scores of the rapid office strain assessment (Section C).

\begin{tabular}{|c|c|c|c|c|c|c|c|c|c|c|c|c|}
\hline \multirow[t]{3}{*}{ No. } & \multicolumn{4}{|c|}{ Mouse } & \multicolumn{4}{|c|}{ Keyboard } & \multicolumn{4}{|c|}{ Section C } \\
\hline & \multicolumn{2}{|c|}{ MSD } & \multicolumn{2}{|c|}{ Ref } & \multicolumn{2}{|c|}{ MSD } & \multicolumn{2}{|c|}{ Ref } & \multicolumn{2}{|c|}{ MSD } & \multicolumn{2}{|c|}{ Ref } \\
\hline & $\%$ & $n$ & $\%$ & $n$ & $\%$ & $n$ & $\%$ & $n$ & $\%$ & $n$ & $\%$ & $n$ \\
\hline 2 & 13.2 & 9 & 13.2 & 9 & 29.4 & 20 & 33.9 & 23 & 0.0 & 0 & 0.0 & 0 \\
\hline 3 & 60.3 & 41 & 50.0 & 34 & 44.1 & 30 & 29.4 & 20 & 52.9 & 36 & 45.6 & 31 \\
\hline 4 & 26.5 & 18 & 36.8 & 25 & 22.1 & 15 & 33.9 & 23 & 11.8 & 8 & 20.6 & 14 \\
\hline 5 & 0.0 & 0 & 0.0 & 0 & 4.4 & 3 & 2.9 & 2 & 32.3 & 22 & 32.2 & 22 \\
\hline 6 & 0.0 & 0 & 0.0 & 0 & 0.0 & 0 & 0.0 & 0 & 2.9 & 2 & 1.5 & 1 \\
\hline
\end{tabular}

MSD, musculoskeletal disorders; Ref, reference group.

No comparison between sub-scores was undertaken as only the final ROSA score was validated in the literature. However, the sub-scores are presented to allow for discussion; Zero scores were removed from the table to allow for ease of reading.

Section C later provided a peripheral score.

whom all had MSD, Collins and O'Sullivan's (2015) study was also in the early forties, with males and females presenting with this complaint at the ages of 40.1 and 40.3 years, respectively. In our study, both the MSD group and the reference group presented with a young mean age, in the early thirties, and this young mean age could be the attributing factor for our findings.

There was no difference for BMI between the two groups. Both groups were classified as being overweight based on the calculations of the mean BMI score (Khosla \& Lowe 1967), with the MSD group and the reference group BMI values at $26.1 \pm 5.3$ and $26.1 \pm 4.9$, respectively. An increased BMI is known to be a risk factor for multi-site pain (De Cássia Pereira Fernandes et al. 2016), as well as lumbar pain (Piranveyseh et al. 2016), neck pain (Wu et al. 2012), leg pain in females and wrist pain in males (Celik et al. 2018). Kaliniene et al. (2013) found that an increased BMI is not associated with neck MSD. Although the study by Kaliniene et al. (2013) was a small study sample, the BMI does not seem to be a risk factor for MSD, but the authors felt that BMI could add to the compounding effect in that it constitutes part of the multifactorial nature of MSD.

Right-handedness in both the MSD and the reference group was determined at $91.2 \%$ and $95.6 \%$, respectively. Righthandedness has been linked to MSD (Oha et al. 2014). However, handedness has been regarded as insignificant by Abaraogu et al. (2018). Both of these studies were conducted on VDU populations in a university setting, however the participants demographics were different as Abaraogu et al. (2018) participants were $54.5 \%$ woman versus the $85 \%$ in the study by Oha et al. (2014). Both the MSD and the reference group in our study were predominantly right-handed, which did not seem to influence MSD in this case, which is similar to the study by Abaraogu et al. (2018). One could speculate that as right-handedness is so prevalent, devices would most likely be set up to be ergonomically sound for right-handed individuals and this could be a contributing factor for the management of associated risks that could lead to MSD. 
Alternatively, left-handed individuals would have adapted to work within a society that is predominantly right-handed and would, therefore, not be influenced by the handedness factor.

The 12-month prevalence rate is similar to other studies with the highest scores in the neck (69.1\%), shoulders (57.4\%), lower back $(41.2 \%)$ and upper back (39.1\%), followed by the hands/wrists (25\%), knees (19.1\%), elbows (5.9\%) and ankles/feet (5.9\%) (Huisstede et al. 2006; Klussmann et al. 2008; Maakip, Keegel \& Oakman 2016; Mirzaei et al. 2014; Oha et al. 2014). The 7-day prevalence rates were found to be slightly higher across all regions, but share the same top four groupings, namely neck (33.9\%), shoulders (27.9\%), lower back (13.2\%) and upper back (16.2\%). The difference between the 12-month prevalence and 7-day prevalence could be because of recall. The shared top-four grouping provides an indication of the risk areas for MSD in the VDU user.

Multi-site pain is common in VDU users (Neupane \& Nygård 2017; Oha et al. 2014). Our results support these findings as many of those living with MSD indicated that they experience multi-site pain, with $77.9 \%(n=53)$ experiencing more than one site of pain. It is a matter of concern that as many as seven participants were found to present with more than five sites of pain, with the majority of participants experiencing two sites of pain. Although the Nordic Musculoskeletal Questionnaire does not establish chronicity, multi-site pain is common in chronic pain individuals (Marchand et al. 2015). Chronic pain could explain this tendency, although chronic pain is complex and further investigation into the mechanisms behind chronic pain is warranted. Alternatively, multi-site pain is said to be a continuum of single-site pain that is sustained by exposure to several risk factors (De Cássia Pereira Fernandes et al. 2016).

The Effort-Reward Ratio in the MSD and the reference group was calculated as less than one, indicating that the rewards are greater than the effort. This is viewed to be positive as it minimised the risk for reduced health, stress and burnout (Koch et al. 2014; Van Vegchel et al. 2005). The effort, reward and reward sub-scores were not different between the two groups.

The over-commitment questions test the ability or inability to withdraw from work and the inclination to provide for an over-the-top effort (Siegrist et al. 2004). Over-commitment is increased in those who have a misconception of the demands of the job, with poor coping strategies (Siegrist 2012) and a distorted perception of their own cost-gains relations (Siegrist 1996). Over-commitment has been associated with poor selfrated health (Siegrist et al. 2004) and intensified stress symptoms (Feldt et al. 2013). The MSD group could be at risk of inflating their own MSD problems through inaccurate recall, and perceived work demands, even though these aspects may be similar for the reference group. Our findings suggest the need to address over-commitment and psychosocial risks in order to maintain an optimal level of occupational health and to minimise disability. Addressing non-reciprocity and over-commitment through psychological detachment, relaxation, mastery and control has been found to be important in the management of the potential risk for burnout and poor recovery (Feldt et al. 2013).

There was no significant difference between the MSD and the reference group's risk assessment scores. These findings support other studies that also found no association between the workstation set-up and MSD (Coelho et al. 2015; Klussmann et al. 2008; Lima \& Coelho 2018; Wu et al. 2012). There are many components to a workstation, and the lack of association between poor ergonomics and MSD may be because of the ROSA assessment method, and components tested. The ROSA has a few challenges which could have contributed to the lack of differentiation between the two groups assessed here. These challenges will be discussed below. The mean value for both groups was a classification of four, thus indicating a medium-risk classification, where scores of five or more require immediate change (Sonne et al. 2012). A score of less than five, however, does not imply that there is no room for improvement; it is still viewed as a risk factor and requires adjustments to the optimum. As only 14 and 16 participants in the MSD group and the reference group, respectively, had scores of three, the remaining participants all had areas to address to minimise risk.

The ROSA also has limitations to the scoring, as one high sub-score can cause a high final score, even though the rest of the workstation is not at risk to the same extent. A score of five or more in the arm and back supports that sub-score assessment would by default result in at least a five final ROSA score. The seat pan height/depth sub-score, a score of six or more on this assessment, would by default result in at least a five final ROSA score.

Not one of the participants had an adjustable seat pan, and hence all would score at least one point in this section. The monitor score reflects the monitor component of the VDU. Risk factors pertain to position, height, distance, non-neutral postures, glare, document holders and duration. All participants were awarded a point for the duration of the work period as, by inclusion, all participants used the VDU for more than $4 \mathrm{~h}$ a day. The lowest a participant could score was a value of two - for the correct distance and level at which the monitor was mounted. The distribution of scores is aligned with the use of multiple monitors, a poor desktop set-up and the laptop components to which the participants assessed had access. Most of the participants' scores increased on account of their unsatisfactory distances from the VDU, the height of the monitor and their neck twist scores.

Both groups had a majority of participants that used a telephone for less than $30 \mathrm{~min}$ a day and were awarded a negative point, resulting in scores of one and two on this subscale. The scores for monitor and telephone were low because of the low telephone scores. As this section contributes to the final ROSA, a very low telephone score decreases the final ROSA score. However, a participant could experience a 
neck twist, a lengthy duration of time and the screen at a high level, thus scoring three. The low telephone score of one or two would result in a section score of two. This is a low-risk score. However, considering all of the literature that nonneutral and awkward postures are known risk factors for MSD (Devereux et al. 2002; Wahlstedt et al. 2010), and should be addressed, such a low score is misleading in a risk assessment. A minimum score of two points would be possible in the keyboard category. One point would be provided for neutral wrists, and as all participants would also be awarded a point for more than $4 \mathrm{~h}$ a day in front of a VDU, the second point would be awarded by this time factor. Scores increased with participants showing wrist extension, wrist deviation and with elevated shoulders. Elevated shoulders would be penalised twice, once at this section of the assessment, and again at the back-support section. Owing to the nature of the participants' job requirements, none of the participants received a score for reaching up to overhead items.

The use of laptops generally influences this score on account of the added wrist extension, deviation and elevated shoulder in order to compensate for neck flexion. The same argument as for the monitor and telephone score applies to this section. As previously mentioned, even a low-physical risk factor should be addressed as a compounding effect emanating from multiple risk factors that affect MSD.

All participants used a pincer grip with the mouse. Duration scores varied, as not all participants required the mouse for the job tasks. Reach and palm rest also influenced these scores. The monitor and peripherals' scores were derived from the keyboard and mouse score, as well as from the monitor and the telephone scores. Any score of five or more in this section would immediately result in a final ROSA of five or more.

The monitor and telephone scores were all under four for both groups. However, the effects of the keyboard score resulted in a higher score at this point. Even though the risk assessment programme does not indicate a high risk for MSD, it does not exclude the fact that participants may still experience risk factors that are not observed in the ergonomic risk assessment.

Using the ROSA as an assessment tool is not an independent measure of physical risk factors, but rather an overview of general workstation risk. Matos and Arezes (2015) noted that the scores in their study may be a result of not poor ergonomic equipment, but rather poor optimisation of the equipment. Sonne et al. (2012) found a correlation value or $r=0.36$, a $13 \%$ rise in discomfort with a rising ROSA score, making the use of the ROSA to measure ergonomic workstation risk and MSD effective in relating MSD to ergonomic risk. The shortcomings of the ROSA do not diminish the value of the risk assessment for physical risks in ergonomic workstation set-up. When comparing the ergonomic risk factors of an MSD group to those of a reference group, the results of our study add to the body of knowledge that workstation set-up alone is not related to MSD (Coelho et al. 2015; Klussmann et al. 2008; Lima \& Coelho 2018; Wu et al. 2012).

Physiotherapists and other healthcare professionals should use their clinical judgement when issuing ergonomic guidelines. The combination of physical and psychosocial risk factors increases the odds for MSD (Korhonen et al. 2003; Widanarko et al. 2014), and by acknowledging this, physiotherapists and other healthcare professionals should be cognisant of giving advice relating to ergonomics only on the basis of physical-risk factors. Assessment and interventions of work-related psychosocial factors should also be considered in the management of MSD.

\section{Strength and limitations}

Validated outcome measures were used throughout this study. The ROSA was completed by the first author only, thus allowing for consistency in the assessments. Although not all of the data were collected on 1 day, the period of data collection was minimised as far as logistically possible. A sample of convenience was used which might not be a true representation of all VDU users in South Africa. The variety of professions and occupations within the various companies' employees of the two sample groups did limit the generalisability of the findings. On account of the ROSA limitations and specificity, as well as the efforts of the participants to improve the workstation as the assessment was being conducted, the ergonomic risk assessment may have limited reach.

\section{Clinical implications}

When educating patients using VDU in terms of their ergonomic workstation, the assessment needs to include all other relevant work-related risk factors, including but not limited to, job demands, job control, stress (psychosocial factors) and individual factors. As multi-site pain is common in individuals living with chronic pain, it could be hypothesised that as chronic pain is complex and multifactorial, interventions to address chronic pain may be warranted in MSD patients working with VDU.

\section{Conclusion}

The use of ergonomic education for patients with MSD should be performed holistically, taking all the workplacerisk factors for MSD into account. As over-commitment is an indication of intrinsic factors and personal characteristics, the significant difference between the MSD group's overcommitment score and that of the reference group suggests that interventions and methods to empower individuals are needed.

\section{Acknowledgements}

The authors would like to acknowledge Dr Annalie Basson for input throughout the write up process, and Dr Nikolas Pautz for his assistance with the statistical analysis. We would like to acknowledge the companies that allowed 
access to their employees and the employees for participation.

\section{Competing interests}

The authors have declared that no competing interest exists.

\section{Authors' contributions}

Both authors were involved in conceptualising the study. V.S.R. put forth the proposal, collected the data and wrote the article. B.O. supervised and revised all drafts from proposal through to the submission of the article.

\section{Funding information}

Financial support was received from the South African Society of Physiotherapy as well as the Faculty Research Committees Individual Grant 2018.

\section{Data availability statement}

Data will be made available upon request from the corresponding author.

\section{Disclaimer}

The views expressed in this article are those of the authors and not an official position of the South African Journal of Physiotherapy or the South African Society of Physiotherapy. The authors declare that they have no financial or personal relationships that may have inappropriately influenced them in writing this article.

\section{References}

Abaraogu, U.O., Okorie, P.N., Duru, D.O. \& Ezenwankwo, E.F., 2018, 'Individual and work-related risk factors for musculoskeletal pain among computer workers in Nigeria', Archives of Environmental and Occupational Health 73(3), 162-168. https://doi.org/10.1080/19338244.2017.1305325

Ardahan, M. \& Simsek, H., 2016, 'Analyzing musculoskeletal system discomforts and risk factors in computer-using office workers', Pakistan Journal of Medical Sciences 32(6), 1425-1429. https://doi.org/10.12669/pjms.326.11436

Bruno Garza, J.L. \& Young, J.G., 2015, 'A literature review of the effects of computer input device design on biomechanical loading and musculoskeletal outcomes during computer work', Work 52(2), 217-230. https://doi.org/10.3233/WOR152161

Celik, S., Celik, K., Dirimese, E., Tasdemir, N., Arik, T. \& Buyukkara, I., 2018, 'Determination of pain in musculoskeletal system reported by office workers and the pain risk factors', International Journal of Occupational Medicine and Environmental Health 31(1), 91-111. https://doi.org/10.13075/ijomeh.1896.00901

Coelho, D.A., Tavares, C.S.D., Lourenço, M.L. \& Lima, T.M., 2015, 'Working conditions under multiple exposures: A cross-sectional study of private sector administrative workers', Work 51(4), 781-789. https://doi.org/10.3233/WOR-152025

Coggon, D., Ntani, G., Palmer, K.T., Felli, V.E., Harari, R. \& Barrero, L.H. et al., 2012, 'The CUPID (cultural and psychosocial influences on disability) study: Methods of data collection and characteristics of study sample', PLoS One 7(7), e39820. https://doi. org/10.1371/journal.pone.0039820

Collins Dictionary, 2018, viewed 30 June 2017, from https://www.collinsdictionary. com/dictionary/english/visual-display-unit.

Collins, J.D. \& O'Sullivan, L.W., 2015, 'Musculoskeletal disorder prevalence and psychosocial risk exposures by age and gender in a cohort of office based employees in two academic institutions', International Journal of Industrial Ergonomics 46, 85-97. https://doi.org/10.1016/j.ergon.2014.12.013

Crawford, J.O., 2007, 'The Nordic musculoskeletal questionnaire', Occupational Medicine 57(4), 300-301. https://doi.org/10.1093/occmed/kqm036

Das, B. \& Ghosh, T., 2010, 'Assessment of ergonomical and occupational health related problems among VDT workers of West Bengal, India', Asian Journal of Medical Sciences 1(2), 26-31. https://doi.org/10.3126/ajms.v1i2.2992
De Cássia Pereira Fernandes, R., Da Silva Pataro, S.M., De Carvalho, R.B. \& Burdorf, A. 2016, 'The concurrence of musculoskeletal pain and associated work-related factors: A cross-sectional study', BMC Public Health 16, article 628. https://doi. factors: A cross-sectional study',
org/10.1186/s12889-016-3306-4

De Jonge, J., Van Der Linden, S., Schaufeli, W., Peter, R. \& Siegrist, J., 2008, 'Factorial invariance and stability of the effort-reward imbalance scales: A longitudinal analysis of two samples with different time lags', International Journal of Behavioral Medicine 15(1), 62-72. https://doi.org/10.1007/BF03003075

Devereux, J.J., Vlachonikolis, I.G. \& Buckle, P.W., 2002, 'Epidemiological study to investigate potential interaction between physical and psychosocial factors at work that may increase the risk of symptoms of musculoskeletal disorder of the neck and upper limb', Occupational and Environmental Medicine 59(4), 269-277. https://doi.org/10.1136/oem.59.4.269

Feldt, T., Huhtala, M., Kinnunen, U., Hyvönen, K., Mäkikangas, A. \& Sonnentag, S., 2013, 'Long-term patterns of effort-reward imbalance and over-commitment: Investigating occupational well-being and recovery', Work and Stress 27(1), 64-87. https://doi.org/10.1080/02678373.2013.765670

Green, B.N., 2008, 'A literature review of neck pain associated with computer use: Public health implications', Journal of the Canadian Chiropractic Association 52(3), 161-168.

Harris, P.A., Taylor, R., Thielke, R., Payne, J., Gonzalez, N. \& Conde, J.G., 2009, 'Research electronic data capture (REDCap) - A metadata-driven methodology and workflow process for providing translational research informatics support', Biomed Inform 42(2), 377-381. https://doi.org/10.1016/j.jbi.2008.08.010

Huisstede, B.M.A., Bierma-Zeinstra, S.M.A., Koes, B.W. \& Verhaar, J.A.N., 2006, 'Incidence and prevalence of upper-extremity musculoskeletal disorders: A systematic appraisal of the literature', BMC Musculoskeletal Disorders 7(1), 7. https://doi.org/10.1186/1471-2474-7-7

Kaliniene, G., Ustinaviciene, R., Skemiene, L. \& Januskevicius, V., 2013, 'Associations between neck musculoskeletal complaints and work related factors among public service computer workers in Kaunas', International Journal of Occupational Medicine and Environmental Health 26(5), 670-681. https://doi.org/10.2478/ s13382-013-0141-z

Khosla, T. \& Lowe, C., 1967, 'Indices of obesity derived from body weight and height', Journal of Epidemiology \& Community Health 21(3), 122-128. https://doi. org/10.1136/jech.21.3.122

Kim, E. \& Kim, J.S., 2016, 'Correlation between rounded shoulder posture, neck disability indices, and degree of forward head posture', Journal of Physical Therapy Science 28(10), 2929-2932. https://doi.org/10.1589/jpts.28.2929

Klussmann, A., Gebhardt, H., Lieber, F. \& Rieger, M.A., 2008, 'Musculoskeletal symptoms of the upper extremities and the neck: A cross-sectional study on
prevalence and symptom-predicting factors at visual display terminal (VDT) prevalence and symptom-predicting factors at visual display terminal (VDT)
workstations', BMC Musculoskeletal Disorders 9, 96. https://doi. workstations', BMC Musculd
org/10.1186/1471-2474-9-96

Koch, P., Schablon, A., Latza, U. \& Nienhaus, A., 2014, 'Musculoskeletal pain and effort-reward imbalance--A systematic review', BMC Public Health 14(37), 37. https://doi.org/10.1186/1471-2458-14-37

Korhonen, T., Ketola, R., Toivonen, R., Luukkonen, R., Häkkänen, M. \& ViikariJuntura, E., 2003, 'Work related and individual predictors for incident neck pain among office employees working with video display units', Occupational and Environmental Medicine 60(7), 475-482. https://doi.org/10.1136/ and Environm

Kuorinka, I., Jonsson, B., Kilbom, A., Vinterberg, H., Biering-Sørensen, F. \& Andersson, G., 1987, 'Standardised Nordic questionnaires for the analysis of musculoskeletal symptoms', Applied Ergonomics 18(3), 233-237. https://doi.org/10.1016/00036870(87)90010-X

Landolt, K., O'Donnell, E., Hazi, A., Dragano, N. \& Wright, B.J., 2017, 'An experimental examination of the effort-reward imbalance model of occupational stress: Increased financial reward is related to reduced stress physiology', Biological Psychology 125, 121-129. https://doi.org/10.1016/j.biopsycho.2017.03.006

Lapointe, J., Dionne, C.E., Brisson, C. \& Montreuil, S., 2013,' Effort-reward imbalance and video display unit postural risk factors interact in women on the incidence of musculoskeletal symptoms', Work 44(2), 133-143. https://doi.org/10.3233/wor2012-1357

Lima, T.M. \& Coelho, D.A., 2018, 'Ergonomic and psychosocial factors and musculoskeletal complaints in public sector administration - A joint monitoring approach with analysis of association', International Journal of Industria Ergonomics 66, 85-94. https://doi.org/10.1016/j.ergon.2018.02.006

Maakip, I., Keegel, T. \& Oakman, J., 2016, 'Prevalence and predictors for musculoskeletal discomfort in Malaysian office workers: Investigating explanatory factors for a developing country', Applied Ergonomics 53(Part A), 252-257. https://doi.org/10.1016/j.apergo.2015.10.008

Maakip, I., Keegel, T. \& Oakman, J., 2017, 'Predictors of musculoskeletal discomfort: A cross-cultural comparison between Malaysian and Australian office workers', Applied Ergonomics 60, 52-57. https://doi.org/10.1016/j.apergo.2016.11.004

Marchand, G.H., Myhre, K., Leivseth, G., Sandvik, L., Lau, B., Bautz-holter, E. et al. 2015 , "Change in pain, disability and influence of fear- avoidance in a workfocused intervention on neck and back pain: a randomized controlled trial', $B M C$ Musculoskeletal Disorders 16(94), 1-11. https://doi.org/10.1186/s12891-015 0553-y

Matos, M. \& Arezes, P.M., 2015, 'Science direct ergonomic evaluation of office workplaces with rapid office strain assessment (ROSA)', Procedia Manufacturing 3, 4689-4694. https://doi.org/10.1016/j.promfg.2015.07.562

Mirzaei, R., Moussavi Najarkola, S.A., Asadi Khanoki, B. \& Ansari, H., 2014 'Comparative assessment of upper limbs musculoskeletal disorders by rapid upper limb assessment among computer users of Zahedan Universities', Health Scope 3(4), e15226. https://doi.org/10.17795/jhealthscope-15226 
Neupane, S. \& Nygård, C.H., 2017, 'Physical and mental strain at work: Relationships with onset and persistent of multi-site pain in a four-year follow up', International Journal of Industrial Ergonomics 60, 47-52. https://doi.org/10.1016/j.ergon.2016.03.005

Oha, K., Animägi, L., Pääsuke, M., Coggon, D. \& Merisalu, E., 2014, 'Individual and work-related risk factors for musculoskeletal pain: A cross-sectional study among Estonian computer users', BMC Musculoskeletal Disorders 15, 181. https://doi. org/10.1186/1471-2474-15-181

Piranveyseh, P., Motamedzade, M., Osatuke, K., Mohammadfam, I., Moghimbeigi, A. Soltanzadeh, A. et al., 2016, 'Association between psychosocial, organizational and personal factors and prevalence of musculoskeletal disorders in office workers', International Journal of Occupational Safety and Ergonomics 22(2), 267-273. https://doi.org/10.1080/10803548.2015.1135568

Poochada, W. \& Chaiklieng, S., 2015, 'Ergonomic risk assessment among call center workers', Procedia Manufacturing 3, 4613-4620. https://doi.org/10.1016/j. promfg.2015.07.543

Ranasinghe, P., Perera, Y.S., Lamabadusuriya, D.A., Kulatunga, S., Jayawardana, N., Rajapakse, S. et al., 2011, 'Work related complaints of neck, shoulder and arm among computer office workers: A cross-sectional evaluation of prevalence and risk factors in a developing country', Environmental Health 10(1), 70. https://doi. org/10.1186/1476-069X-10-70

Rodrigues, M.S.A., Leite, R.D.V., Lelis, C.M. \& Chaves, T.C., 2017, 'Differences in ergonomic and workstation factors between computer office workers with and

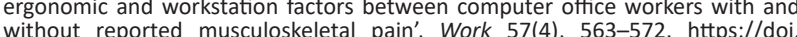
without reported musculosk
org/10.3233/WOR-172582

Siegrist, J., 1996, 'Adverse health effects of high-effort/low-reward conditions', Journal of Occupational Health Psychology 1(1), 27-41. https://doi.org/10.1037/1076of Occupationc

Siegrist, J., 2012, Effort-reward imbalance at work - Theory, measurement and evidence, Dusseldorf University, Dusseldorf.

Siegrist, J., Li, J. \& Montano, D., 2014, Psychometric properties of the effort-reward imbalance questionnaire, pp. 1-14, Department of Medical Sociology, Faculty of Medicine, Duesseldorf University, Germany.

Siegrist, J., Starke, D., Chandola, T., Godin, I., Marmot, M., Niedhammer, I. et al., 2004 'The measurement of effort-reward imbalance at work: European comparisons', Social Science and Medicine 58(8), 1483-1499. https://doi.org/10.1016/S0277 9536(03)00351-4

Silva, C., Barros, C., Cunha, L., Carnide, F. \& Santos, M., 2014, 'Prevalence of back pain problems in relation to occupational group', International Journal of Industria Ergonomics 52, 52-58. https://doi.org/10.1016/j.ergon.2015.08.005

Sonne, M., Villalta, D.L. \& Andrews, D.M., 2012, 'Development and evaluation of an office ergonomic risk checklist: ROSA - Rapid office strain assessment', Applied Ergonomics 43(1), 98-108. https://doi.org/10.1016/j.apergo.2011.03.008

Sun, Y., Nimbarte, A.D. \& Motabar, H., 2017, 'Physical risk factors associated with the workrelated neck/cervical musculoskeletal disorders: A review', Industrial and Systems related neck/cervical musculoskeletal disorders: A review', Industrial and System
Engineering Review 5(1), 44-60. https://doi.org/10.37266/ISER.2017v5i1.pp44-60
Van Eerd, D., Munhall, C., Irvin, E., Rempel, D., Brewer, S., Van Der Beek, A.J. et al., 2016, 'Effectiveness of workplace interventions in the prevention of upper extremity musculoskeletal disorders and symptoms: An update of the evidence' Occupational and Environmental Medicine 73(1), 62-70. https://doi.org/10.1136/ Occupational and Enviror

Van Vegchel, N., Jonge, J., Bosma, H. \& Schaufeli, W., 2005, 'Reviewing the effortreward imbalance model: Drawing up the balance of 45 empirical studies', Social Science and Medicine 60(5), 1117-1131. https://doi.org/10.1016/j. socscimed.2004.06.043

Van Vledder, N. \& Louw, Q., 2015, 'The effect of a workstation chair and computer screen height adjustment on neck and upper back musculoskeletal pain and sitting comfort in office workers', South African Journal of Physiotherapy 71(1), 10. https://doi.org/10.4102/sajp.v71i1.279

Wahlstedt, K., Norbäck, D., Wieslander, G., Skoglund, L. \& Runeson, R., 2010, 'Psychosocial and ergonomic factors, and their relation to musculoskeletal complaints in the Swedish workforce', International Journal of Occupational Safety and Ergonomics 16(3), 311-321. https://doi.org/10.1080/10803548.2010. 11076848

Wahlstrom, J., 2005, 'Ergonomics, musculoskeletal disorders and computer work', Occupational Medicine 55(3), 168-176. https://doi.org/10.1093/ occmed/kqi083

Werth, A. \& Babski-Reeves, K., 2014, 'Effects of portable computing devices on posture, muscle activation levels and efficiency', Applied Ergonomics 45(6), 1603-1609. https://doi.org/10.1016/j.apergo.2014.05.008

Widanarko, B., Legga, S., Devereux, J. \& Stevenson, M., 2014, 'The combined effect of physical, psychosocial/organisational and/or environmental risk factors on the presence of work-related musculoskeletal symptoms and its consequences', Applied Ergonomics 45(6), 1610-1621. https://doi.org/10.1016/j.apergo.2014. 05.018

Woo, E.H.C., White, P. \& Lai, C.W.K., 2016, 'Ergonomics standards and guidelines for computer workstation design and the impact on users' health - a review', Ergonomics 59(3), 464-475. https://doi.org/10.1080/00140139.2015. 1076528

Wu, S., He, L., Li, J., Wang, J. \& Wang, S., 2012, 'Visual display terminal use increases the prevalence and risk of work-related musculoskeletal disorders among Chinese office workers: A cross-sectional study', Journal of Occupational Health Psychology 54(1), 34-43. https://doi.org/10.1539/joh.11-0119-OA

Yue, P., Xu, G., Li, L. \& Wang, S., 2014, 'Prevalence of musculoskeletal symptoms in relation to psychosocial factors', Occupational Medicine 64(3), 211-216. https:// doi.org/10.1093/occmed/kqu008

Zakerian, S. \& Subramanian, I, 2011, 'Examining the relationship between psychosocial work factors and musculoskeletal discomfort among computer users in Malaysia', Iranian Journal of Public Health 40(1), 72-79. 